\title{
Reconsidering Animal Models of Major Depressive Disorder in the Elderly
}

\author{
Shigenobu Toda ${ }^{1,2,3 *}$, Yoshio Iguchi ${ }^{4}$, Ziqiao Lin ${ }^{1}$, Hiromi Nishikawa ${ }^{1}$, \\ Tatsuya Nagasawa ${ }^{1,3}$, Hirotaka Watanabe ${ }^{5}$ and Yoshio Minabe ${ }^{1,2,3}$ \\ ${ }^{1}$ Department of Psychiatry and Neurobiology, Kanazawa University, Kanazawa, Japan, ${ }^{2}$ Research Center for Child Mental \\ Development, Kanazawa University, Kanazawa, Japan, ${ }^{3}$ Hokuriku Dementia Professional Physician Training Plan, Kanazawa, \\ Japan, ${ }^{4}$ Department of Molecular Genetics, Institute of Biomedical Sciences, Fukushima Medical University, Fukushima, \\ Japan, ${ }^{5}$ Department of Physiology, Keio University School of Medicine, Tokyo, Japan
}

Keywords: major depressive disorder, elderly people, dementia, neurodegeneration, animal model

\section{INTRODUCTION}

Major depressive disorder (MDD) is a common psychiatric illness with high morbidity that poses a huge burden to healthcare systems worldwide. According to the World Health Organization, the lifetime prevalence of MDD is approximately 3-17\% globally (Richards, 2011). However, after major, but limited, success with selective serotonin reuptake inhibitors (SSRIs) or serotonin-noradrenaline reuptake inhibitors, few promising therapeutic approaches have been developed from preclinical studies using current animal models of MDD, despite intensive research involving laborious methods and substantial costs.

Traditionally, most research using rodent models of MDD has been conducted using relatively young adult animals, aged approximately 8 weeks, to avoid any involvement of aging-related biological factors. The major rationale of this strategy is based on epidemiological findings that the occurrence of MDD displays a robust peak in young adults rather than in the elderly (Jorm, 2000; Copeland et al., 2004; Blazer and Hybels, 2005). Further, the elderly may have aging-related factors rendering this group an inappropriate model of "genuine" MDD. A critical question is whether this strategy is indeed appropriate. Despite the consistent findings of a lower lifetime prevalence rate of MDD in the elderly than in young adults, there remain persistent doubts regarding the underdiagnosis of MDD in the elderly (Hoertel et al., 2013). It has been heavily argued that patients diagnosed with MDD in youth will often be rediagnosed with a bipolar disorder (Lish et al., 1994; Leonpacher et al., 2015). Thus, a considerable number of cases of MDD in young adults may be misdiagnosed. In addition, MDD in the elderly has distinct biological/environmental backgrounds and consequences compared with that in young adults.

In this opinion article, we primarily shed light on the significance of MDD in the elderly (known as geriatric MDD or late-onset depression) and problems associated with the methodology of preclinical studies undertaken to investigate the characteristics and treatment of this disorder.

\section{INFLUENCES OF AGING ON PHYSIOLOGICAL FUNCTIONS}

First, it is widely accepted that functional changes in motor or cognitive functions in the elderly, including those related to learning and memory, are attributed to aging-induced physiological changes (Mora et al., 2007; Grady, 2012; Limdenberger, 2014). For example, aging of

Abbreviations: A $\beta$, amyloid- $\beta$; AD, Alzheimer's disease; BDNF, brain-derived neurotropic factor; CSF, cerebrospinal fluid; MDD, major depressive disorder; SSRI, selective serotonin reuptake inhibitor. 
the dopaminergic system is one of the major factors responsible for motor disturbances in the elderly. However, the patients with Parkinson's disease may demonstrate dysregulated habits and learning abilities before manifesting motor disturbance as a result of dorsal striatum damage (Hadj-Bouziane et al., 2013). This type of inconspicuous dysfunction may be sufficient to affect the ability of the elderly to perform normal daily activities, which consequentially generates frustration, exhaustion, and compromised self-esteem. Meanwhile, the effect of aging on the serotonergic or noradrenergic system, which plays a pivotal role in the pathophysiology of MDD (Blier and El Mansari, 2013; Fakhoury, 2015), remains to be elucidated in rodents and humans, although a decline in serotonin transport in the elderly both in human and non-human primates (Kakiuchi et al., 2001; Yamamoto et al., 2002) may result not only in mood instability but also in being short-tempered or easily giving up in the elderly (Miyazaki et al., 2012). Besides neurotransmitters, aginginduced decreases in neurotropic factors, such as brain-derived neurotropic factor (BDNF), which is essential for neuronal plasticity, may also be involved in cognitive dysfunction (Burke and Barnes, 2006; Tapia-Arancibia et al., 2008).

Current major hypotheses to explain the molecular mechanisms underlying MDD, such as a deficit of BDNF (Duman and Monteggia, 2006), dopamine (Nestler and Carlezon, 2006; Dreher et al., 2008), serotonin, or stress-induced attenuation of neurogenesis (Lazarov et al., 2010; Hamilton et al., 2013). However, these potential mechanisms are more suitable for aged than younger brains because these alterations commonly become eminent during the natural course of aging. Other agingrelated macro/microstructural changes, such as vascular changes, weakened immune/cytokine responses, compromised redox status, a loss of dendritic spines, and reduced neuronal plasticity, may also account for the pathophysiology of MDD (Burke and Barnes, 2006; Lucin and Wyss-Coray, 2009; Currais and Maher, 2013; Gutchess, 2014). All these physiological systems maintain resilience as long as they function appropriately. However, once malfunction begins, it may result in the loss of resilience, namely an increased prevalence of damaging symptoms such as cognitive impairment (Butters et al., 2004), pseudo-dementia, and delusions (Alexopoulos, 2005), which occur less often in young adults. These symptoms are related to the higher rate of recurrence of MDD in the elderly (Maeshima et al., 2012) and complicate the treatment of these patients. Executive functions and decision-making abilities may be similarly affected (Buckner, 2004; Breton et al., 2015; Samanez-Larkin and Knutson, 2015).

\section{CAUSAL RELATIONSHIP BETWEEN MDD AND DEMENTIA IN THE ELDERLY}

Second, researchers has recently argued the possibility of MDD as a precursor or risk factor for Parkinson's disease (Fang et al., 2010; Inoue et al., 2010; Shen et al., 2013; Gustafsson et al., 2015), mild cognitive impairment (Panza et al., 2010; Richard et al., 2013; Snowden et al., 2015), dementia with Lewy bodies (Boot et al., 2013), vascular dementia (Barnes et al., 2012; Diniz et al., 2013; Taylor et al., 2013), Alzheimer's disease (AD; Green et al., 2003;
Ownby et al., 2006; Geerlings et al., 2008; Barnes et al., 2012; Diniz et al., 2013), or general aging-related cognitive disorders (Byers and Yaffe, 2011; da Silva et al., 2013; Sibille, 2013). As mentioned before, MDD in the elderly often accompanies pseudo-dementia, which alleviates when MDD is attenuated but not completely in many cases (Alexopoulos, 2005), implying a continuum of deterioration from MDD to dementia in the elderly. In support of this concept, MDD in the elderly often involves a greater degree of severe brain atrophy and/or white matter hyperintensity than that in the age-matched healthy controls (Herrmann et al., 2008; Dotson et al., 2009; Köhler et al., 2010; Tham et al., 2011; Geerlings et al., 2013; Ribeiz et al., 2013; Khundakar and Thomas, 2014).

Given that depression in the elderly is a precursor of dementia, depression should always precede the onset of dementia, and concomitantly coexist at the initial or transitional stage of dementia. However, given the considerable prevalence of depression without cognitive impairment in the elderly (Pellegrino et al., 2013), in some cases, MDD may boost, rather than prelude, dementia. At this point, whether a history of depression is a precursor for dementia remains an issue of debate.

Even in case that MDD is not the precursor for neurodegenerative disorders, the process of neurodegeneration, in turn, may cause vulnerability against MDD from a very early stage. For example, Lewy bodies or senile plaques appear in the brain at a relatively early point in life, while the consequence could be subclinical in terms of cognitive function. However, the appearance of plaques, albeit a subthreshold of the manifestation of motor or cognition impairment, may provide sufficient vulnerability to stress for triggering MDD by gradually damaging physiological resilience (Jagust, 2013). In this scenario, MDD is not a precursor but rather a sinister overture of dementia. The increase of $A \beta$ levels in the cerebrospinal fluid (CSF) in patients with MDD supports this idea (Osorio et al., 2014). Intriguingly, SSRIs, which are not effective against the core symptoms of $\mathrm{AD}$, were found to decrease $\mathrm{A} \beta$ levels in CSF in both healthy individuals and AD model mice (Sheline et al., 2014), suggesting that $\mathrm{AD}$ pathology is reversible, at least to some extent, and is not sufficient to develop dementia by itself.

\section{FURTHER PROMISING RELATIONSHIPS BETWEEN STRESS AND DEMENTIA}

Meanwhile, the causal relationship between chronic stress and dementia has been repeatedly supported by many preclinical studies (Csernansky et al., 2006; Sotiropoulos et al., 2008; Dong and Csernansky, 2009; Rissman, 2009). For example, chronic stress or glucocorticoid augmentation induces tau pathology in rat brain (Catania et al., 2009; Carroll et al., 2011), as well as cognitive impairment in rats (Rissman et al., 2007, 2012; Sotiropoulos et al., 2011). Corticotropin releasing factor accelerates $\mathrm{A} \beta$ production in AD models (Dong et al., 2012). In addition, chronic mild stress accelerates the onset and progression of AD-like phenotypes in Tg2576 mice (CuadradoTejedor et al., 2012). Moreover, stress not only induces posttraumatic stress disorder-like phenotypes but also more 
easily elevates $\mathrm{A} \beta$ levels in $\mathrm{AD}$ model animals compared with wild-type animals (Justice et al., 2015). However, in these studies, MDD-like symptoms or treatment-resistance to antidepressants were not assessed. Thus, at this point, it is still inconclusive whether they are the models of dementia which includes depression as one of the initial symptoms or pseudo-dementia in elderly MDD. Meanwhile, clinical studies have not yet addressed the effect of psychological stress on dementia. On the contrary, it is well known that cognitive enrichment or social engagement can delay the onset of dementia, even with the same load of AD pathology (Stern, 2006; Fratiglioni and Wang, 2007), which further supports the idea that MDD may boost dementia as an additional factor by affecting these positive factors.

\section{OTHER FACTORS THAT EXAGGERATE MDD IN THE ELDERLY}

Other factors that are not directly connected to the aging of the brain, such as the presence of comorbid illnesses and corresponding pharmacological treatment for these illnesses, social isolation, or spousal loss, could predispose, or deteriorate MDD in the elderly. Overall, in the elderly, vulnerability to stress is more profound. Thus, it is highly likely that depression-like phenotypes may be more easily inducible by various stressors in the elderly than in young adults (summarized in Figure 1A). In addition, because of the abovementioned multiple complicated factors, MDD in the elderly demonstrates diverse individual differences both in symptoms and responses to antidepressants, resulting in treatment failure and higher recurrence in the elderly than in young adults (Reynolds et al., 1999).

\section{ESSENTIAL PRECLINICAL STUDIES FOR ELUCIDATING THE MOLECULAR PATHOPHYSIOLOGY UNDERLYING MDD IN THE ELDERLY}

Taken together, two current models regarding the relationship between MDD, and dementia in the elderly are summarized (Figure 1B). In the first model, stress induces dementia-related pathology and MDD independently and the co-existence of the two will result in dementia, indicating that the presence of MDD promotes the development of dementia (i.e., booster model). In this sense, the full remission of MDD in the elderly may be more important to prevent future dementia. In the second model, stress induces dementia-related pathology to a point sufficient for the development of dementia; MDD appears as a prodromal symptom of dementia (i.e., precursor model). In this case, to halt the ensuing symptoms, it is important to elucidate the molecular

A

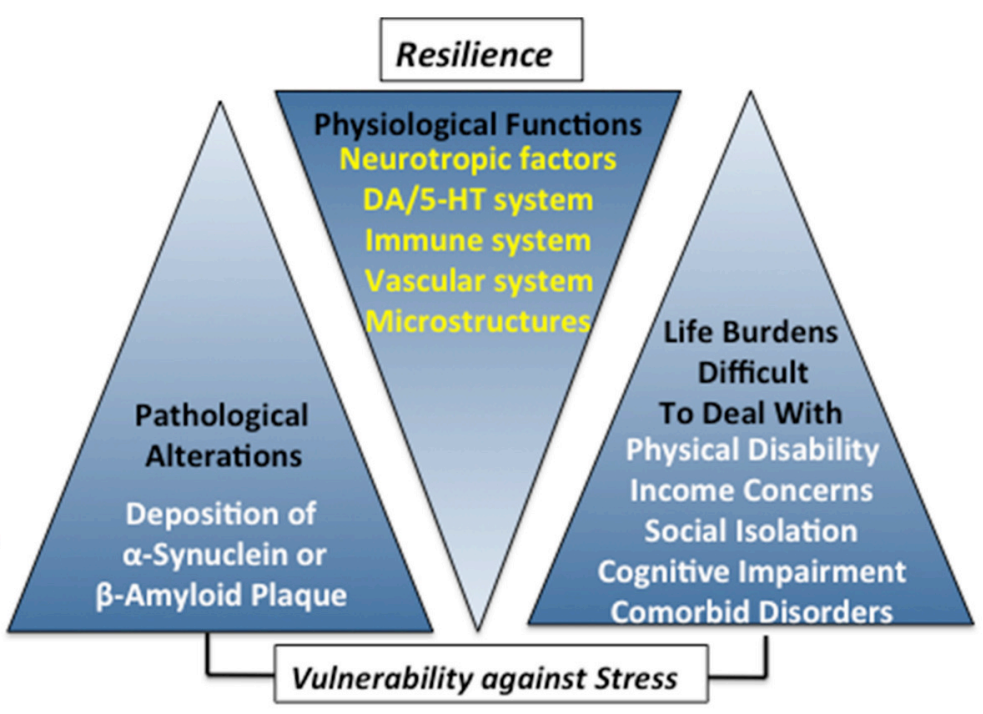

B

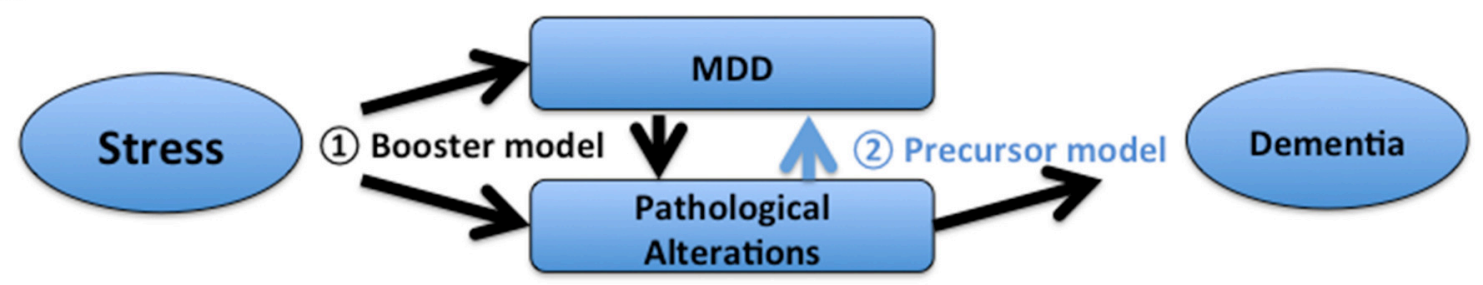

FIGURE 1 | (A) Relationship between aging-related factors in patients with dementia and MDD. (B) Two models for understanding the causal relationship between MDD and dementia. 
mechanisms underlying the development and manifestation of depression (Gareri et al., 2002; Krishnan, 2002; Alexopoulos and Kelley, 2009; Naismith et al., 2012).

We propose a methodology to verify which model is correct. To verify the "booster" model, it is important to determine whether AD-related pathology is sufficient to induce MDD-like symptoms without other stress in rodents (Llorens-Martin et al., 2011). In turn, it would be intriguing to address the effect of subclinical AD-related pathology on the vulnerability to stress in animal models of dementia before the exhibition of robust cognitive or motor dysfunction at certain ages by exposure to other types of stress that may induce MDD. Relatively young or middle-aged animals are appropriate for this purpose and are used in the most current preclinical studies. On the other hand, to verify the second model, resistance to treatment with antidepressants and persistence of these pathological alterations, cognitive impairments, which are the hallmarks of dementia, and MDD-like symptoms need to be fully addressed in stressinduced AD models. Given that MDD is a part of dementia as this scenario, it is expected that there will be very fewer resilience cases in the elderly than in young adults. In addition, other types of "pure" psychological stressors that evoke MDD-like phenotypes, such as social defeat (Berton et al., 2006), should be examined to reproduce similar consequences. Hence, such studies require aged rodents.

\section{REFERENCES}

Alexopoulos, G. S. (2005). Depression in the elderly. Lancet 365, 1961-1970. doi: 10.1016/S0140-6736(05)66665-2

Alexopoulos, G. S., and Kelley, R. E. Jr. (2009). Research advances in geriatric depression. World Psychiatry 8, 140-149. doi: 10.1002/j.20515545.2009.tb00234.x

Barnes, D. E., Yaffe, K., Byers, A. L., McCormick, M., Schaefer, C., and Whitmer, R. A. (2012). Midlife vs late-life depressive symptoms and risk of dementia: differential effects for Alzheimer disease and vascular dementia. Arch. Gen. Psychiatry 69, 493-498. doi: 10.1001/archgenpsychiatry.2011.1481

Berton, O., McClung, C. A., Dileone, R. J., Krishnan, V., Renthal, W., Russo, S. J., et al. (2006). Essential role of BDNF in the mesolimbic dopamine pathway in social defeat stress. Science 311, 864-868. doi: 10.1126/science.1120972

Blazer, D. G. II., and Hybels, C. F. (2005). Origins of depression in later life. Psychol. Med. 35, 1241-1252. doi: 10.1017/S0033291705004411

Blier, P., and El Mansari, M. (2013). Serotonin and beyond: therapeutics for major depression. Philos. Trans. R. Soc. Lond. B. Biol. Sci. 368, 20120536. doi: 10.1098/rstb.2012.0536

Boot, B. P., Orr, C. F., Ahlskog, J. E., Ferman, T. J., Roberts, R., Pankratz, V. S., et al. (2013). Risk factors for dementia with Lewy bodies: a case-control study. Neurology 81, 833-840. doi: 10.1212/WNL.0b013e3182a2cbd1

Breton, Y.-A., Seeland, K. D., and Redish, A. D. (2015). Aging impairs deliberation and behaveoral flexibility in inter-temporal choice. Front. Aging Neurosci. 7:41. doi: 10.3389/fnagi.2015.00041

Buckner, R. L. (2004). Memory and executive function in aging and AD: multiple factors that cause decline and reserve factors that compensate. Neuron 44, 195-208. doi: 10.1016/j.neuron.2004.09.006

Burke, S. N., and Barnes, C. A. (2006). Neural plasticity in the ageing brain. Nat. Rev. Neurosci. 7, 30-40. doi: 10.1038/nrn1809

Butters, M. A., Whyte, E. M., Nebes, R. D., Begley, A. E., Dew, M. A., Mulsant, B. H., et al. (2004). The nature and determinants of neuropsychological functioning in late-life depression. Arch. Gen. Psychiatry 61, 587-595. doi: 10.1001/archpsyc.61.6.587
Our proposed studies may appear to be an amalgamation of various interdependent aging-related factors rather than a "genuine" model of MDD. However, they may mimic both actual clinical situations and the brain states of patients at the onset of MDD better than conventional animal models of MDD. These approaches may allow us to conclude a causal relationship between MDD and dementia in the elderly. In addition, they may help to develop novel treatment regimens to not only alleviate the symptoms of MDD but also prevent the onset of dementia in the elderly.

\section{AUTHOR CONTRIBUTIONS}

ST, YI, LZ, HN, TN, HW, and YM designed and wrote the manuscript.

\section{ACKNOWLEDGMENTS}

This study was supported by Grants-in-Aids from the Ministry of Education, Culture, Sports and Technology, Japan (26860920 to HN; 25461727, 25116510, and 26120712 to ST) and a grant from Comprehensive Research on Disability, Japan Agency for Medical Research and Development (AMED; H26-SeishinIppan-016 to ST).

Byers, A. L., and Yaffe, K. (2011). Depression and risk of developing dementia. Nat Rev. Neurol. 7, 323-331. doi: 10.1038/nrneurol.2011.60

Carroll, J. C., Iba, M., Bangasser, D. A., Valentino, R. J., James, M. J., Brunden, K. R., et al. (2011). Chronic stress exacerbates tau pathology, neurodegeneration, and cognitive performance through a corticotropin-releasing factor receptordependent mechanism in a transgenic mouse model of tauopathy. J. Neurosci. 31, 14436-14449. doi: 10.1523/JNEUROSCI.3836-11.2011

Catania, C., Sotiropoulos, I., Silva, R., Onofri, C., Breen, K. C., Sousa, N., et al. (2009). The amyloidogenic potential and behavioral correlates of stress. Mol. Psychiatry 14, 95-105. doi: 10.1038/sj.mp.4002101

Copeland, J. R., Beekman, A. T., Braam, A. W., Dewey, M. E., Delespaul, P., Fuhrer, R., et al. (2004). Depression among old people in Europe: the EURODEP studies. World Psychiatry 3, 45-49.

Csernansky, J. G., Dong, H., Fagan, A. M., Wang, L., Xiong, C., Holzman, D. M., et al. (2006). Plasma cortisol and progression of dementia in subjects with Alzheimer-type dementia. Am. J. Psychiatry 163, 2164-2169. doi: 10.1176/ajp.2006.163.12.2164

Cuadrado-Tejedor, M., Ricobaraza, A., Frechilla, D., Franco, R., Perez-Mediavilla, A., and Garcia-Osta, A. (2012). Chronic mild stress accelerates the onset and progression of the Alzheimer's disease phenotype in Tg2576 mice. J. Alzheimers. Dis. 28, 567-578. doi: 10.3233/JAD-2011-110572

Currais, A., and Maher, P. (2013). Functional consequences of age-dependent changes in glutathione status in the brain. Antioxid. Redox Signal. 19, 813-822. doi: 10.1089/ars.2012.4996

da Silva, J., Gonçalves-Pereira, M., Xavier, M., and Mukaetova-Ladinska, E. B. (2013). Affective disorders and risk of developing dementia: systematic review. Br. J. Psychiatry 202, 177-186. doi: 10.1192/bjp.bp.111.101931

Diniz, B. S., Butters, M. A., Albert, S. M., Dew, M. A., and Reynolds, C. F. III. (2013). Late-life depression and risk of vascular dementia and Alzheimer's disease: systematic review and meta-analysis of community-based cohort studies. Br. J. Psychiatry 202, 329-335. doi: 10.1192/bjp.bp.112.118307

Dong, H., and Csernansky, J. G. (2009). Effects of stress and stress hormones on amyloid-beta protein and plaque deposition. J. Alzheimers. Dis. 18, 459-469. doi: 10.3233/JAD-2009-1152 
Dong, H., Murphy, K. M., Meng, L., Montalvo-Ortiz, J., Zeng, Z., Kolber, B. J., et al. (2012). Corticotrophin releasing factor accelerates neuropathology and cognitive decline in a mouse model of Alzheimer's disease. J. Alzheimers. Dis. 28, 579-592. doi: 10.3233/JAD-2011-111328

Dotson, V. M., Davatzikos, C., Kraut, M. A., and Resnick, S. M. (2009). Depressive symptoms and brain volumes in older adults: a longitudinal magnetic resonance imaging study. J. Psychiatry Neurosci. 34, 367-375.

Dreher, J. C., Meyer-Lindenberg, A., Kohn, P., and Berman, K. F. (2008). Age-related changes in midbrain dopaminergic regulation of the human reward system. Proc. Natl. Acad. Sci. U.S.A. 105, 15106-15111. doi: 10.1073/pnas.0802127105

Duman, R. S., and Monteggia, L. M. (2006). A neurotrophic model for stress-related mood disorders. Biol. Psychiatry 59, 1116-1127. doi: 10.1016/j.biopsych.2006.02.013

Fakhoury, M. (2015). Revisiting the serotonin hypothesis: implications for major depressive disorders. Mol. Neurobiol. 53, 2778-2786. doi: 10.1007/s12035-0159152-z

Fang, F., Xu, Q., Park, Y., Huang, X., Hollenbeck, A., Blair, A., et al. (2010). Depression and the subsequent risk of Parkinson's disease in the NIH-AARP Diet and Health Study. Mov. Disord. 25, 1157-1162. doi: 10.1002/mds.23092

Fratiglioni, L., and Wang, H. X. (2007). Brain reserve hypothesis in dementia. J. Alzheimers. Dis. 12, 11-22.

Gareri, P., De Fazio, P., and De Sarro, G. (2002). Neuropharmacology of depression in aging and age-related diseases. Ageing Res. Rev. 1, 113-134. doi: 10.1016/S0047-6374(01)00370-0

Geerlings, M. I., den Heijer, T., Koudstaal, P. J., Hofman, A., and Breteler, M. M. (2008). History of depression, depressive symptoms, and medial temporal lobe atrophy and the risk of Alzheimer disease. Neurology 70, 1258-1264. doi: 10.1212/01.wnl.0000308937.30473.d1

Geerlings, M. I., Sigurdsson, S., Eiriksdottir, G., Garcia, M. E., Harris, T. B., Sigurdsson, T., et al. (2013). Associations of current and remitted major depressive disorder with brain atrophy: the AGES-Reykjavik Study. Psychol. Med. 43, 317-328. doi: 10.1017/S0033291712001110

Grady, C. (2012). The cognitive neuroscience of ageing. Nat. Rev. Neurosci. 13, 491-505. doi: 10.1038/nrn3256

Green, R. C., Cupples, L. A., Kurz, A., Auerbach, S., Go, R., Sadovnick, D., et al. (2003). Depression as a risk factor for Alzheimer disease: the MIRAGE Study. Arch. Neurol. 60, 753-759. doi: 10.1001/archneur.60.5.753

Gustafsson, H., Nordström, A., and Nordström, P. (2015). Depression and subsequent risk of Parkinson disease: a nationwide cohort study. Neurology 84, 2422-2429. doi: 10.1212/WNL.0000000000001684

Gutchess, A. (2014). Plasticity of the aging brain: new directions in cognitive neuroscience. Science 346, 579-582. doi: 10.1126/science.1254604

Hadj-Bouziane, F., Benatru, I., Brovelli, A., Klinger, H., Thobois, S., Broussolle, E., et al. (2013). Advanced Parkinson's disease effect on goal-directed and habitual processes involved in visuomotor associative learning. Front. Hum. Neurosci. 6:351. doi: 10.3389/fnhum.2012.00351

Hamilton, L. K., Joppé, S. E. M., Cochard, L., and Fernandes, K. J. (2013). Aging and neurogenesis in the adult forebrain: what we have learned and where we should go from here. Eur. J. Neurosci. 37, 1978-1986. doi: 10.1111/ejn.12207

Herrmann, L. L., Le Masurier, M., and Ebmeier, K. P. (2008). White matter hyperintensities in late life depression: a systematic review. J. Neurol. Neurosurg. Psychiatr. 79, 619-624. doi: 10.1136/jnnp.2007.124651

Hoertel, N., Le Strat, Y., Gorwood, P., Béra-Potelle, C., Schuster, J. P., Manetti, A., et al. (2013). Why does the lifetime prevalence of major depressive disorder in the elderly appear to be lower than in younger adults? Results from a national representative sample. J. Affect. Disord. 149, 160-165. doi: 10.1016/j.jad.2013.01.017

Inoue, T., Kitagawa, M., Tanaka, T., Nakagawa, S., and Koyama, T. (2010). Depression and major depressive disorder in patients with Parkinson's disease. Mov. Disord. 25, 44-49. doi: 10.1002/mds.22921

Jagust, W. (2013). Vulnerable neural systems and the borderland of brain aging and neurodegeneration. Neuron 77, 219-234. doi: 10.1016/j.neuron.2013.01.002

Jorm, A. F. (2000). Does old age reduce the risk of anxiety and depression? A review of epidemiological studies across the adult life span. Psychol. Med. 30, 11-22. doi: $10.1017 /$ S0033291799001452

Justice, N. J., Hunag, L., Tian, J. B., Cole, A., Pruski, M., Hunt, A. J., et al. (2015). Posttraumatic stress disorder-like induction elevates $\beta$-amyloid levels, which directly activates corticotropin-releasing factor neurons to exacerbate stress responses. J. Neurosci. 35, 2612-2623. doi: 10.1523/JNEUROSCI.333314.2015

Kakiuchi, T., Tsukada, H., Fukumoto, D., and Nishiyama, S. (2001). Effects of aging on serotonin transporter availability and its response to fluvoxamine in the living brain: PET study with $[(11) \mathrm{C}](+) \mathrm{McN} 5652$ and [(11)C](-)McN5652 in conscious monkeys. Synapse 40, 170-179. doi: 10.1002/ syn.1039

Khundakar, A. A., and Thomas, A. J. (2014). Cellular morphometry in late-life depression: a review of postmortem studies. Am. J. Geriatr. Psychiatry 22, 122-132. doi: 10.1016/j.jagp.2013.06.003

Köhler, S., Thomas, A. J., Lloyd, A., Barber, R., Almeida, O. P., and O’Brien, J. T. (2010). White matter hyperintensities, cortisol levels, brain atrophy and continuing cognitive deficits in late-life depression. Br. J. Psychiatry 196, 143-149. doi: 10.1192/bjp.bp.109.071399

Krishnan, K. R. (2002). Biological risk factors in late life depression. Biol. Psychiarty 52, 185-192. doi: 10.1016/S0006-3223(02)01349-5

Lazarov, O., Mattson, M. P., Peterson, D. A., Pimplikar, S. W., and van Praag, H. (2010). When neurogenesis encounters aging and disease. Trends Neurosci. 33, 569-579. doi: 10.1016/j.tins.2010.09.003

Leonpacher, A. K., Liebers, D., Pirooznia, M., Jancic, D., MacKinnon, D. F., Mondimore, F. M., et al. (2015). Distinguishing bipolar from unipolar depression: the importance of clinical symptoms and illness features. Psychol. Med. 45, 2437-2446. doi: 10.1017/s0033291715000446

Limdenberger, U. (2014). Human cognitive aging: corriger la fortune? Science 346, 572-578. doi: 10.1126/science. 1254403

Lish, J. D., Dime-Meenan, S., Whybrow, P. C., Price, R. A., and Hirschfeld, R. M. (1994). The National Depressive and Manic-depressive Association (DMDA) survey of bipolar members. J. Affect. Dis. 31, 281-294. doi: 10.1016/01650327(94)90104-X

Llorens-Martin, M., Hernandez, F., and Avila, J. (2011). Expression of frontotemporal dementia with parkinsonism associated to chromosome 17 tau induces specific degeneration of the ventral dentate gyrus and depressive-like behavior in mice. Neuroscience 196, 215-227. doi: 10.1016/j.neuroscience.2011.08.057

Lucin, K. M., and Wyss-Coray, T. (2009). Immune activation in brain aging and neurodegeneration: too much or too little? Neuron 64, 110-122. doi: 10.1016/j.neuron.2009.08.039

Maeshima, H., Baba, H., Nakano, Y., Satomura, E., Namekawa, Y., Takebayashi, N., et al. (2012). Residual memory dysfunction in recurrent major depressive disorder-a longitudinal study from Juntendo University Mood Disorder Project. J. Affect. Dis. 143, 84-88. doi: 10.1016/j.jad.2012. 05.033

Miyazaki, K., Miyazaki, K. W., and Doya, K. (2012). The role of serotonin in the regulation of patience and impulsivity. Mol. Neurobiol. 45, 213-224. doi: 10.1007/s12035-012-8232-6

Mora, F., Segovia, G., and del Arco, A. (2007). Aging, plasticity and environmental enrichment: structural changes and neurotransmitter dynamics in several areas of the brain. Brain Res. Rev. 55, 78-88. doi: 10.1016/j.brainresrev.2007. 03.011

Naismith, S. L., Norrie, L. M., Mowszowski, L., and Hickie, I. B. (2012). The neurobiology of depression in later-life: clinical, neuropsychological, neuroimaging and pathophysiological features. Prog. Neurobiol. 98, 99-143. doi: 10.1016/j.pneurobio.2012.05.009

Nestler, E. J., and Carlezon, W. A. Jr. (2006). The mesolimbic dopamine reward circuit in depression. Biol. Psychiatry 59, 1151-1159. doi: 10.1016/ j.biopsych.2005.09.018

Osorio, R. S., Gumb, T., and Pomara, N. (2014). Soluble amyloid- $\beta$ levels and late-life depression. Curr. Pharm. Des. 20, 2547-2554. doi: 10.2174/ 13816128113199990502

Ownby, R. L., Crocco, E., Acevedo, A., John, V., and Loewenstein, D. (2006). Depression and risk for Alzheimer disease: systematic review, metaanalysis, and metaregression analysis. Arch. Gen. Psychiatry 63, 530-538. doi: 10.1001/archpsyc.63.5.530

Panza, F., Frisardi, V., Capurso, C., D’Introno, A., Colacicco, A. M., and Imbimbo, B. P. (2010). Late-life depression, mild cognitive impairment, and dementia: possible continuum? Am. J. Geriatr. Psychiary 18, 98-116. doi: 10.1097/JGP.0b013e3181b0fa13 
Pellegrino, L. D., Peters, M. E., Lyketsos, C. G., and Marano, C. M. (2013). Depression in cognitive impairment. Curr. Psychiatry Rep. 15:384. doi: 10.1007/s11920-013-0384-1

Reynolds, C. F. III., Frank, E., Perel, J. M., Imber, S. D., Cornes, C., Miller, M. D., et al. (1999). Nortriptyline and interpersonal psychotherapy as maintenance therapies for recurrent major depression: a randomized controlled trial in patients older than 59 years. JAMA 281, 39-45. doi: 10.1001/jama.281.1.39

Ribeiz, S. R., Duran, F., Oliveira, M. C., Bezerra, D., Castro, C. C., Steffens, D. C., et al. (2013). Structural brain changes as biomarkers and outcome predictors in patients with late-life depression: a cross-sectional and prospective study. PLoS ONE 8:e80049. doi: 10.1371/journal.pone.0080049

Richard, E., Reitz, C., Honig, L. H., Schupf, N., Tang, M. X., Manly, J. J., et al. (2013). Late-life depression, mild cognitive impairment, and dementia. JAMA Neurol. 70, 374-382. doi: 10.1001/jamaneurol.2013.603

Richards, D. (2011). Prevalence and clinical course of depression: a review. Clin. Psychol. Rev. 31, 1117-1125. doi: 10.1016/j.cpr.2011.07.004

Rissman, R. A. (2009). Stress-induced tau phosphorylation: functional neuroplasticity or neuronal vulnerability? J. Alzheimers. Dis. 18, 453-457. doi: 10.3233/JAD-2009-1153

Rissman, R. A., Lee, K. F., Vale, W., and Sawchenko, P. E. (2007). Corticotropin-releasing factor receptors differentially regulate stressinduced tau phosphorylation. J. Neurosci. 27, 6552-6562. doi: 10.1523/ JNEUROSCI.5173-06.2007

Rissman, R. A., Staup, M. A., Lee, A. R., Justice, N. J., Rice, K. C., Vale, W., et al. (2012). Corticotropin-releasing factor receptor-dependent effects of repeated stress on tau phosphorylation, solubility, and aggregation. Proc. Natl. Acad. Sci. U.S.A. 109, 6277-6282. doi: 10.1073/pnas. 1203140109

Samanez-Larkin, G. R., and Knutson, B. (2015). Decision making in the ageing brain: changes in affective and motivational circuits. Nat. Rev. Neurosci. 16, 278-289. doi: 10.1038/nrn3917

Sheline, Y. I., West, T., Yarasheski, K., Swarm, R., Jasielec, M. S., Fisher, J. R., et al. (2014). An antidepressant decreases CSF A $\beta$ production in healthy individuals and in transgenic $\mathrm{AD}$ mice. Sci. Transl. Med. 6, 236re4. doi: 10.1126/scitranslmed.3008169

Shen, C. C., Tsai, S. J., Perng, C. L., Kuo, B. I., and Yang, A. C. (2013). Risk of Parkinson disease after depression: a nationwide population-based study. Neurology 81, 1538-1544. doi: 10.1212/WNL.0b013e3182a956ad

Sibille, E. (2013). Molecular aging of the brain, neuroplasticity, and vulnerability to depression and other brain-related disorders. Dialog. Clin. Neurosci. 15, 53-65.
Snowden, M. B., Atkins, D. C., Steinman, L. E., Bell, J. F., Bryant, L. L., Copeland, C., et al. (2015). Longitudinal association of dementia and depression. Am. J. Geriatr. Psychiary 23, 897-905. doi: 10.1016/j.jagp.2014.09.002

Sotiropoulos, I., Catania, C., Pinto, L. G., Silva, R., Pollerberg, G. E., Takashima, A., et al. (2011). Stress acts cumulatively to precipitate Alzheimer's diseaselike tau pathology and cognitive deficits. J. Neurosci. 31, 7840-7847. doi: 10.1523/JNEUROSCI.0730-11.2011

Sotiropoulos, I., Cerqueira, J. J., Catania, C., Takashima, A., Sousa, N., and Almeida, O. F. (2008). Stress and glucocorticoid footprints in the brain-the path from depression to Alzheimer's disease. Neurosci. Biobehav. Rev. 32, 1161-1173. doi: 10.1016/j.neubiorev.2008.05.007

Stern, Y. (2006). Cognitive reserve and Alzheimer disease. Alzheimer Dis. Assoc. Disord. 20 (Suppl. 2), S69-S74. doi: 10.1097/00002093-200607001-00010

Tapia-Arancibia, L., Aliaga, E., Silhol, M., and Arancibia, S. (2008). New insights into brain BDNF function in normal aging and Alzheimer disease. Brain Res. Rev. 59, 201-220. doi: 10.1016/j.brainresrev.2008.07.007

Taylor, W. D., Aizenstein, H. J., and Alexopoulos, G. S. (2013). The vascular depression hypothesis: mechanisms linking vascular disease with depression. Mol. Psychiatry 18, 963-974. doi: 10.1038/mp.2013.20

Tham, M. W., Woon, P. S., Sum, M. Y., Lee, T. S., and Sim, K. (2011). White matter abnormalities in major depression: evidence from post-mortem, neuroimaging and genetic studies. J. Affect. Disord. 132, 26-36. doi: 10.1016/j.jad.2010. 09.013

Yamamoto, M., Suhara, T., Okubo, Y., Ichimiya, T., Sudo, Y., Inoue, M., et al. (2002). Age-related decline of serotonin transporters in living human brain of healthy males. Life Sci. 71, 751-757. doi: 10.1016/S0024-3205(02) 01745-9

Conflict of Interest Statement: The authors declare that the research was conducted in the absence of any commercial or financial relationships that could be construed as a potential conflict of interest.

Copyright (C) 2016 Toda, Iguchi, Lin, Nishikawa, Nagasawa, Watanabe and Minabe. This is an open-access article distributed under the terms of the Creative Commons Attribution License (CC BY). The use, distribution or reproduction in other forums is permitted, provided the original author(s) or licensor are credited and that the original publication in this journal is cited, in accordance with accepted academic practice. No use, distribution or reproduction is permitted which does not comply with these terms. 